\title{
Of babies and bathwater: balancing support and challenge in a 'was not brought' approach to children's missed dental appointments
}

\author{
Jenny C. Harris ${ }^{1}$
}

\section{Key points}

Encourages adoption of a 'was not brought' (WNB) approach to children's missed denta appointments, putting the child's right to healthcare centre stage.
Explains the in-built features of a published WNB pathway which help to avoid unresolved cases or disguised compliance.
Advises that managing dental neglect and missed appointments requires a balance of providing support to families together with appropriate challenge.

\begin{abstract}
Prompted by a recent Letter to the Editor describing another team's experience of implementing the Sheffield 'was not brought' pathway for children and young people's missed dental appointments (WNB-CYP), its author reflects on the reasoning behind certain deliberate features of the pathway and the place of the WNB approach within the wider context of dentistry's involvement in safeguarding children.
\end{abstract}

\section{Introduction}

'Sorry I did not attend my appointment but I can't see over the steering wheel yet and I don't have enough pocket money to get the bus'. So begins the wavering voice of a serious little girl voicing a two-minute animation produced to explain to health professionals why they should be concerned about children's missed appointments. ${ }^{1}$ In recent years, she has accompanied me at conferences and webinars as I have lectured on dental neglect to a variety of professional audiences, outshining my carefully prepared PowerPoint slides and stealing the show, rightfully putting a child's perspective at the centre of our efforts in safeguarding.

I had first come to know about the drive to reconceptualise 'did not attend' (DNA) or 'failed to attend' (FTA) to 'was not brought' (WNB) almost a decade ago, via Powell and

${ }^{1}$ Consultant in Community Paediatric Dentistry, Charles Clifford Dental Services, Sheffield Teaching Hospitals NHS Foundation Trust, Community \& Special Care Dentistry, Wheata Place Dental Clinic, Wordsworth Avenue, Sheffield, S5 9JH, UK.

Correspondence to: Jenny Harris

Email address: jenny.harris@nhs.net

Accepted 4 March 2021

https://doi.org/10.1038/s41415-021-3218-2
Appleton's review paper $^{2}$ in a nursing journal, and by sharing in conversations at conferences of the International Society for the Prevention of Child Abuse and Neglect (ISPCAN) and its British counterpart, the Association of Child Protection Professionals (AoCPP, formerly BASPCAN), when presenting work on safeguarding in relation to dentistry. In safeguarding circles, dentistry was already known for having a big problem with missed appointments. Many of the children who most needed treatment were being denied their right to healthcare because they were not being brought through our doors.

In my own workplace, a city-wide community dental service (CDS), we had been working on a long-running clinical audit - but we had got stuck. Despite being alert to children's missed dental appointments as a possible indicator of neglect (Table 1), we were seemingly unable to communicate consistently enough with other professionals to make sure that children could never slip through our net. ${ }^{4}$ When I talked to colleagues at regional paediatric dentistry network meetings, we all felt as if we were drowning in DNA admin for little gain and, crucially, still risked failing the vulnerable children and young people (CYP) who needed us most. It called for a new start. Taking a clean sheet of paper and numerous shared examples of what hadn't worked across the region, I set about designing a new pathway and promised I would get back to them.

\section{A new pathway}

Our aim was to produce a practical solution to encourage earlier and more consistent information sharing about safeguarding

Table 1 Diagnosing dental neglect: features of particular concern, adapted with permission from J. Harris, 'Dental neglect in children', Paediatrics and Child Health, 2012, Elsevier, ${ }^{3}$ updated to reflect 'was not brought' terminology

\begin{tabular}{|c|c|}
\hline Feature of concern & Further explanation \\
\hline Obvious dental disease & $\begin{array}{l}\text { Untreated dental disease, particularly when obvious to a layperson or non- } \\
\text { dental health professional }\end{array}$ \\
\hline Significant impact on the child & $\begin{array}{l}\text { Evidence that dental disease has had a significant impact on the child, } \\
\text { such as a history of pain or infection }\end{array}$ \\
\hline Not brought for dental care & $\begin{array}{l}\text { Parents or carers have access to acceptable dental care but persistently do } \\
\text { not bring the child for treatment }\end{array}$ \\
\hline
\end{tabular}


concerns using a standardised approach and making the most of the skills of the whole dental team. We wanted to play our part in identifying children at risk of neglect but, importantly, also to reach a defined end point at which we could consider dentistry's efforts concluded and responsibilities fulfilled. We hoped to produce something easy to learn and apply consistently, without need for additional resources. Altogether, quite a tall order.

After six months of testing with my own patients, multiple iterations of content and layout, and consultation with our local Named Professionals for Safeguarding, in January 2016, our clinic started using the new WNB-CYP 'green' pathway for all children and young people. I knew the pathway had prompted me and my immediate team to do what needed doing, but when it came to the crunch, would it work for others? The timely involvement in the project of a Leadership Fellow in Safeguarding Children enabled us to evaluate that in detail.

What we found was something of a pleasant surprise. Not only were we more consistent, but also staff talked with enthusiasm about the new approach. Managing missed appointments was no longer a chore. The simple swap to WNB terminology had changed their attitude and shifted the focus onto the child. They told us that using the pathway relieved their uncertainty and supported them in decisionmaking, teamwork and interprofessional communication without increasing their daily workload; ${ }^{5}$ not bad for something that is simply a flowchart, some template patient notes, and letters to parents and general medical practitioners (GMPs).

After a bit of fine-tuning, we rolled the pathway out across the service. Now in the hands of 22 dentists at seven CDS clinics, the results were similar: good uptake (actioned for $89.3 \%$ of missed appointments) and prompting information sharing for $28.0 \%$ of 143 children who missed appointments in a six-month period. ${ }^{5}$ Further work, as yet not peer-reviewed, showed that GMPs receiving our letters found them appropriate, important and helpful. ${ }^{6}$ We then shared the WNB-CYP pathway with the profession in September $2019,{ }^{5}$ with the addition of a concise toolkit ${ }^{7}$ from the British Dental Association (BDA) to aid implementation in other settings. Then we went back to the day job.

\section{What happened next?}

A year later, I was interested to see a British Dental Journal Letter to the Editor ${ }^{8}$ reporting a team's experience of successfully implementing the WNB-CYP pathway in their own public dental practice in Scotland. In keeping with our own findings, it was pleasing to see their observation that immediate phone calls to parents after children's missed appointments promoted patient engagement, and using the pathway prompted substantial improvement in interprofessional information sharing for safeguarding and promoting welfare. Like us, they had had to develop a system to make sure that repeated cancellations did not go unnoticed.

Published resources often need to be adapted for use in different settings and in consultation with local stakeholders, so I was intrigued to see the amendments to the pathway that their team chose to make, in case we could learn from their experience. Their vulnerable client group sounded very similar to our own and the tone of their letter spoke of working with parents in a supportive and inclusive manner - the kind of team I like working in, the kind of team I think I'd like to care for me if I was a patient.

The key amendment they had made was to post out a new appointment even when unable to contact the parent after a WNB. With this change, I fear the loss of some of the WNBCYP pathway's benefits. This prompted me to reflect on why we do what we do. For others considering the WNB-CYP pathway and deciding whether to adopt or amend it, it might be helpful to explain the reasoning behind some perhaps counter-intuitive yet deliberate features of the original pathway. It would be a shame if the baby was thrown out with the bathwater.

\section{Why we do what we do}

After a WNB, we do not simply send a further appointment unless we have first made contact with the parent. This is based on Kvist et al.'s observation that 'just arranging for a new appointment will result in another missed appointment.' We have come to believe that to send further appointments without first contacting the parent does the child no favours, may compound a pattern of not bringing the child and may even mistakenly imply our collusion that it is acceptable to miss appointments. Instead, if there is no response to our phone calls or letter within three weeks, we now promptly assess risk of harm, share information with other professionals (such as health visitor, school nurse or social worker) if risk is high (or not, in cases where the impact of non-attendance on the child is considered minimal), write a 'WNB4 letter' to the GMP and then archive the records. Thus, we reach a defined end point at which our efforts can be considered concluded. We tell it straight: 'This child is not under the care of a dentist'. We no longer sit on an ever-growing pile of 'unsolved cases' who rarely or never attend. We no longer aid the parents in prolonged periods of disguised compliance.

Interestingly, many return soon after, often prompted by their GMP or other health or social care professional. We welcome them back and are pleased to fast track them back into care. Yet, we believe there is value in our prior clear end point to focus attention - both our attention and that of other professionals. We had never before seen such a level of supportive engagement from our local GMPs.

Importantly, we are prepared to let go those children whom we have assessed to be at lowest risk of harm. While we are always reluctant, there is a difference between a child who was caries-free when last seen who misses an appointment for fluoride varnish and one who has had repeated emergency antibiotics but has not yet been brought to complete the referral for the general anaesthetic extractions they so desperately need, with all the shades of grey in between.

Note that if we have significant concerns about neglect (whether general neglect or dental neglect), we will have already made a child protection referral to children's social care, or even better, we will have identified the need for support at a much earlier stage and referred the family for early help to the local multi-agency support team or equivalent, ideally pre-empting any missed appointments. For CYP who are the subject of a child protection plan (CPP) or who are looked after (LAC), the dental team must always additionally share information with the child's social worker and escalate any unresolved cases promptly, as recognised in the 'pink' WNBCPP/LAC pathway, one of two variant WNB pathways newly added to the BDA toolkit., ${ }^{710}$

\section{The wider context}

Missed appointments may arguably be dentistry's biggest safeguarding issue, but they are not the only one. Likewise, a pathway for managing them, whether our WNBCYP toolkit or any other, is only one tool among many needed along with supporting knowledge, skills and resources. ${ }^{11,12,13}$ Using 
guidelines is known to reduce uncertainty and increase reporting of concerns. ${ }^{14}$ Table 2 gives examples from my own case load of the wide scope of concerns for which we need to be prepared.

It is important to add that the current COVID-19 pandemic has placed some children at increased risk of abuse and neglect. This comes at a time when they have had lengthy periods of lockdown with markedly less contact with education and health services where their voices might be heard and their needs seen. ${ }^{17}$ Many families are facing additional hardships and challenges, such as unemployment, illness or bereavement. Therefore, considerable clinical judgement will be required in assessing individual cases to achieve the right balance when interpreting WNB policies. However, be aware, and beware, that as adults, we tend to empathise most readily with the adults in the situation rather than with the child. The child's welfare is paramount. ${ }^{18}$ My watchword when managing dental neglect and missed appointments is 'support and challenge': I aim to give generous support together with gentle challenge. Further information is readily available in published guidance $^{11,12}$ and advice is always available from your local safeguarding children professionals when in doubt how to proceed.

\section{Conclusion}

As a profession, we have come a long way in a relatively short time to play our part in safeguarding children who attend our dental surgeries. Yet we have often felt powerless to help those who are not brought through our doors, sometimes those very children who most urgently need care. I hope that a WNB approach will displace DNA and FTA to prove its worth as an addition to the dental toolbox for safeguarding children, as much in other dental services as it has done in my own.

\section{Acknowledgements}

Thank you to my colleague Jen Kirby for her dedication to evaluating the pathway while a Leadership Fellow in Paediatric Dentistry funded by Health Education
Table 2 Ten selected examples of safeguarding concerns observed in specialist paediatric dental practice, reproduced with permission from J. Harris, 'The mouth and maltreatment: safeguarding issues in child dental health', Archives of Disease in Childhood, 2018, BMJ Publishing Group ${ }^{15}$

\begin{tabular}{|c|c|c|}
\hline Case* & $\begin{array}{l}\text { Category of } \\
\text { maltreatment } \\
\text { suspected }\end{array}$ & Scenario and identified concerns \\
\hline 1 & Neglect & $\begin{array}{l}\text { Eleven-year-old boy with autism; delay seeking treatment for severe toothache } \\
\text { affecting eating, sleeping and school participation; missed appointment to } \\
\text { assess need for dental extractions under general anaesthesia; dental neglect }\end{array}$ \\
\hline 2 & Neglect & $\begin{array}{l}\text { Siblings aged seven and six years; missed clinic appointments for routine } \\
\text { dental care; parental mental health problems; repeated toothache and acute } \\
\text { dental infections; dental neglect }\end{array}$ \\
\hline 3 & Physical abuse & $\begin{array}{l}\text { Six-year-old boy with neurodisability; fractured front tooth noted by school; } \\
\text { had not sought dental care; no explanation for an injury which would have } \\
\text { required considerable force }\end{array}$ \\
\hline 4 & Physical abuse & $\begin{array}{l}\text { Four-year-old; perplexing presentation; mismatch between reported } \\
\text { symptoms and observed oral condition; inappropriate requests for prescription } \\
\text { medication; suspected fabricated or induced illness }\end{array}$ \\
\hline 5 & Emotional abuse & $\begin{array}{l}\text { Thirteen-year-old girl; concerning parent-child interaction observed at dental } \\
\text { appointments; mother blaming child for dental anxiety, making derogatory } \\
\text { remarks about child's appearance and scapegoating in comparison to siblings }\end{array}$ \\
\hline 6 & Emotional abuse & $\begin{array}{l}\text { Fourteen-year-old boy; recent behavioural change; child and mother disclosed } \\
\text { witnessing violent incident in the home and father self-harming }\end{array}$ \\
\hline 7 & Emotional neglect & $\begin{array}{l}\text { Seven-year-old girl; concerning parent-child interaction observed at dental } \\
\text { appointments; parent unresponsive and seemingly indifferent to child's need } \\
\text { for comforting and encouragement }\end{array}$ \\
\hline 8 & Other & $\begin{array}{l}\text { Ten-year-old boy; repeated dental injuries; credible accidental explanations; } \\
\text { delayed presentation for treatment but attributed to dental anxiety; mother } \\
\text { smelled strongly of alcohol }{ }^{16}\end{array}$ \\
\hline 9 & Other & $\begin{array}{l}\text { Ten-year-old with complex needs missing from education; moved into the area } \\
\text { without registering for school; not accessing any other healthcare provision }\end{array}$ \\
\hline 10 & Other & $\begin{array}{l}\text { Twelve-year-old girl; mother unaware of child's daily tooth brushing routine; } \\
\text { child lives at a friend's house because mother works nights; undisclosed } \\
\text { private fostering arrangement }\end{array}$ \\
\hline \multicolumn{3}{|c|}{$\begin{array}{l}\text { Key: } \\
*=\text { selected from the author's case load in community clinic (cases } 1-9) \text { or dental hospital settings (case 10) in the period 2003-2016. } \\
* *=\text { similar scenarios to cases } 1 \text { and } 2 \text { are frequently encountered. }\end{array}$} \\
\hline
\end{tabular}

England Yorkshire and the Humber, and to Nottingham City Safeguarding Children Partnership for generously allowing me to use their animation in my teaching.

\section{Conflict of interest}

Jenny Harris is an Honorary Member of Council of the NSPCC, awarded in 2018 in recognition of commitment to the development and promotion of safeguarding practice in dentistry. She served as the British Society of Paediatric Dentistry's Safeguarding Children Representative from 2007 to 2020.

\section{References}

1. Nottingham City Council, NHS Nottingham City CCG, Nottingham City Safeguarding Children Board. Rethinking 'Did Not Attend'. 2017. Available at https:// youtu.be/dAdNL6d4lpk (accessed February 2021).

2. Powell C, Appleton J V. Children and young people's missed health care appointments: reconceptualising 'Did Not Attend' to 'Was Not Brought' - a review of the evidence for practice. J Res Nurs 2012; 17: 181-192.

3. Harris J. Dental neglect in children. Paediatr Child Health 2012: 22: 476-482.

4. Harris J C, Firth L M, Chadwick B L. Clinical audit of children's missed dental appointments in a city-wide salaried community dental service in relation to guidance on when to suspect child maltreatment. Child Abuse Rev 2017; 26: 172-183

5. Kirby J, Harris J C. Development and evaluation of a 'was not brought' pathway: a team approach to managing children's missed dental appointments. BrDent J 2019; 227: 291-297.

6. Kirby J, Harris J. General practitioners' perspectives on a 'was not brought' letter. Int J Paediatr Dent 2019; 29 (Suppl 2): 14

7. British Dental Association. Implementing 'Was Not Brought' in your practice: a tool for safeguarding children who miss appointments. 2020. Available online at www. bda.org/safeguarding (accessed February 2021).

8. Denholm K. Letter to the editor: Implementing 'Was Not Brought'. Br Dent J 2020; 229: 76

9. Kvist T, Malmberg F, Boqvist A-K, Larheden H, Dahllöf. Clinical routines and management of suspected child abuse or neglect in Public Dental Service in Sweden. Swed Dent J 2012; 36: 15-23.

10. British Orthodontic Society Clinical Governance Directorate 'Was Not Brought' Pathway. 2019. Available at https:// www.bos.org.uk/Professionals-Members/DirectoratesCommittees-Groups/Directorates/Clinical-Governance/ Was-Not-Brought-Pathway (accessed February 2021).

11. Harris J, Sidebotham P, Welbury R et al. Child protection and the dental team: an introduction to safeguarding children in dental practice. 2006. Available online at https://bda.org/ childprotection/ (accessed February 2021).

12. Harris J C, Balmer R C, Sidebotham P D. British Society of Paediatric Dentistry: a policy document on dental neglect in children. Int J Paediatr Dent 2009; DOI: 10.1111/j.1365-263X.2009.00996.x.

13. Public Health England. Safeguarding in general dental practice: a toolkit for dental teams. 2019. Available at https:// assets.publishing.service.gov.uk/government/uploads/ system/uploads/attachment_data/file/791681/Guidance_ for_Safeguarding_in_GDP.pdf(accessed June 2021).

14. Rønneberg A, Nordgarden H, Skaare A B, Willumsen T. Barriers and factors influencing communication between dental professionals and Child Welfare Services in their everyday work. Int J Paediatr Dent 2019; 29: 684-691.

15. Harris J C. The mouth and maltreatment: safeguarding issues in child dental health. Arch Dis Child 2018; 103: 722-729.

16. Harris $J C$, Ford $A$, Smith $M$, Barnes P. A reassuring experience. Br Dent J 2006; 201: 189.

17. Jacob H. Safeguarding children in a pandemic: pandemonium with possibility? Child Abuse Rev 2020; 29: 493-496.

18. UK Government. Children Act 1989. Available at https:// www.legislation.gov.uk/ukpga/1989/41/contents (accessed June 2021). 